\title{
PENINGKATAN KOMPETENSI MICROCONTROLLER SISWA SMK
}

\author{
Zaenal Arifin ${ }^{1}$, Teguh Tamrin ${ }^{2}$ \\ ${ }^{1}$ Universitas Islam Nahdlatul Ulama Jepara. \\ email: zaenalarifin elektro@unisnu.ac.id \\ Universitas Islam Nahdlatul Ulama Jepara. \\ email: teguh@unisnu.ac.id
}

\begin{abstract}
The increased interest in students in the field of Electronic Control is influenced by many factors, with family backgrounds, relationships, future expectations, development of science and technology and teachers. The implementation of the Community Service Program Based on Development of Foster Schools in Manba'ul Huda Dukuhseti, Pati Vocational School with the activities in the form of training and assistance in the use of electronic and computer software skills as additional knowledge in developing $H R$ capabilities. Student Competency Improvement Training Related to Electronic and Computer Control Systems, namely programming and Arduino Uno application to create a led light control that can function according to a program made by each student. Through Arduino Uno training this makes science more for students in deepening microcontrollers. Keywords: electronic control, software, Arduino Uno
\end{abstract}

Keywords: electronic control, software, arduinoi uno.

\section{ABSTRAK}

Peningkatan minat siswa pada bidang Control Elektronik dipengaruhi oleh banyak faktor, dengan latar belakang keluarga, pergaulan, harapan masa depan, perkembangan IPTEK dan guru. Pelaksanaan Program Pengabdian Kepada Masyarakat Berbasis Pengembangan Sekolah Binaan ini di SMK Manba'ul Huda Dukuhseti, Pati dengan kegiatan berupa Pelatihan dan pendampingan keterampilan penggunaan software elektronika dan Komputer sebagai ilmu tambahan dalam pengembangan kemampuan SDM. Pelatihan Peningkatan Kompetensi Siswa Terkait dengan Sistem Control Elektronik dan Komputer yaitu pemrograman dan aplikasi Arduino Uno untuk membuat control lampu led yang bisa difungsikan sesuai program yang dibuat oleh masing- masing siswa. Melalui pelatihan Arduino Uno ini menjadikan ilmu lebih bagi siswa dalam mendalami microcontroller.

Kata Kunci: control elektronik, software, arduino uno.

\section{PENDAHULUAN}

Masa depan dan kemajuan bangsa terletak pada kemampuan peserta didik mengikuti perkembangan ilmu pengetahuan dan teknologi. Sekolah Menengah Kejuruan (SMK) merupakan salah satu lembaga pendidikan formal tingkat menengah atas di Indonesia. SMK mempersiapkan lulusan agar mengetahui perkembangan ilmu dan teknologi serta mampu bersaing di dunia industri. SMK sebagai lembaga formal memiliki, bidang, program, dan paket 
keahlian yang berbeda-beda menyesuaikan lapangan kerja yang ada di dunia industri. Siswa SMK dilatih keterampilan dan dididik agar profesional di bidang keahlian masing-masing. (Wiranto:2015).

SMK diharapkan menghasilkan lulusan berkarakter, mampu mengembangkan keunggulan lokal, dan dapat bersaing di dunia industri.Dengan meningkatkan kualitas siswa khusunya dalam bidang Elektronika dan komputer di SMK Manba'ul Huda, akan menghasilkan output yang bagus bagi perkembangan siswa, sekolah maupun daerah setempat. (Wiranto:2015). Elektronika merupakan ilmu yang membidangi pengaturan arus lemah yang sering diaplikasikan dalam dunia controller.(Hibawanto:2012)

Permasalahan yang dihadapi oleh mitra di antaranya dapat dibagi menjadi dua hal, yakni: Kurangnya kesadaran untuk mengikuti trend perkembangan teknologi dalam bidang Control Elektronik dan Komputer, masih mempelajari dasar elektronik dan komputer dasar yang cenderung belum up to date. Belum ada solusi yang tepat untuk memfasilitasi peningkatan kompetensi ssiswa dalam bidang Control Elektronik dan Komputer, perlu peningkatan kualitas dan kuantitas siswa.

Dari 2 permasalahan yang dihadapi, mitra dan tim pengusul bersepakat bahwa urut-urutan prioritas permasalahan yang harus segera ditangani adalah: 1. Pengetahuan tentang dampak jangka panjang akibat trend perkembangan teknologi di bidang Control Elektronik dan Komputer harus ditingkatkan supaya tidak tertinggal oleh zaman dan mengikuti trend saat ini. (Pujriyanto:2009). 2. Memfasilitasi peningkatan kompetensi siswa dalam bidang Control Elektronik dan Komputer dengan cara mengadakan pelatihan sebagai bentuk wujud nyata Perguruan Tinggi dalam melaksanakan Tri Dharma.

Sedangkan Target Luaran yang diharapkan dapat dicapai setelah pelaksanaan Program Pengabdian Kepada Masyarakat ini adalah : 1. Siswa yang sudah memiliki basic mata pelajaran controller akan meningkat kemampuan skillnya dalam penguasaan aplikasi Arduino Uno. 2.Model praktek sistem Komputer sebagai nilai lebih dalam pengembangan kemampuan SDM. 3. Siswa yang kompetititf dalam microcontroller akan meningkat kualitasnya dalam pemanfaatan aplikasi Arduino. Sehingga dengan adanya pelatihan ini akan meningkatkan kualitas dan kuantitas kemampuan siswa khususnya dalam pemrograman Arduino Uno.

\section{METODE PELAKSANAAN}

Metode pelaksanaan kegiatan pengabdian ini adalah dengan melakukan observasi terlebih dahulu ke lokasi pengabdian. Hal ini dilakukan untuk mengidentifikasi metode pengabdian apa yang sesuia dengan kondisi mitra dilapangan, sehingga bisa tepat sasaran. Berdasarkan hasil observasi akan diidentifkasi sebagai bahan acuan untuk melaksanakan pelatihan yang tepat. 
Peralatan elektronika kebanyakan menggunakan baterai sebagai sumber dayanya, Sumber arus adalah sumbet tenaga listrik yang mensuplai arus pada rangkaian listrik. Bagaimanapun besarnya beban pada rangkaian tersebut, besarnya arus relatif tidak berubah kecuali dalam kondisi hubungan terbuka. Besar kecilnya tegangan tergantung pada kondisi beban. (Malvino:2010).

Partisipasi dari mitra dalam kegiatan adalah sebagai peserta pelatihan keterampilan dan pendampingan. Selanjutnya mitra ikut membantu dalam pembuatan dan penerapan Kompetensi Guru maupun siswa dalam mempersiapkan kemampuan soft skill yang dimiliki. (Musfah:2012). Peranan ini dibutuhkan di bidang elektronika dan Program Microcontroller SMK Manba'ul Huda Dukuhseti, Pati.

Tahap pelaksanaan program pengabdian kepada masyarakat ini adalah berupa: Pelatihan Kompetensi Siswa di bidang elektronika, Pelatihan Pembuatan Program Microcontroller untuk siswa. Pendampingan Pembuatan Program Microcontroller untuk siswa dan Workshop insatalasi dasar Jaringan Komputer untuk siswa. Terkait dengan hal tersebut, berikut ini dijelaskan tentang metode yang dipakai dalam pengembangan program pengabdian kepada masyarakat tersebut diatas :

1. Pelatihan Kompetensi Siswa di bidang elektronika. Pelatihan ini bertujuan agar guru memiliki pengetahuan lebih yang memadai tentang cara penggunaan software microcontroller yang efektif, efisien dan memperhatikan aspek inovasi, serta guru mampu membuat dan menerapkan software microcontroller yang tepat dan valid.

2. Pelatihan Pembuatan Program Aplikasi Arduino Unovuntuk siswa. Pelatihan ini bertujuan agar siswa sebagai objek pengajaran juga memiliki pengetahuan lebih yang memadai tentang cara penggunaan software microcontroller yang efektif, efisien dan memperhatikan aspek inovasi.

3. Pendampingan Pembuatan Program aplikasi Arduino Uno untuk siswa. Pendampingan ini bertujuan agar siswa dalam mengaplikasikan penggunaan software microcontroller yang nantinya diharapkan siswa mampu membuat dan menerapkan software microcontroller yang tepat dalam pengaplikasiannya.

\section{HASIL DAN PEMBAHASAN}

Hasil dari program pengabdian ini adalah siswa mampu mengaplikasikan dan menerapkan software microcontroller Arduino Uno. Pelatihan yang diadakan selama satu bulan dengan dua kali pertemuan setiap minggunya. Dimana minggu pertama sebagai pembekalan materi. Minggu kedua dan minggu ketiga pelatihan dan pendampingan pembuatan program software microcontroller Arduino Uno dengan simulasi dan terkoneksi dengan alat. Minggu keempat sebagai penilaian dari hasil program yang diuji cobakan untuk mengetahui kemampuan masing-masing siswa, mulai dari tahap pembuatan aplikasi, simulasi dan penerapan pada control lampu led. 
Pelatihan yang direncanakan dengan jumlah peserta siswa SMK sebanyak 40 siswa baik laki-laki maupun perempuan kelas XI jurusan Elektro dan audio video dalam pelatihan peningkatan kompetensi bagi Siswa terkait dengan Sistem Control Elektronik dan Komputer di SMK Manba'ul Huda Dukuhseti, Pati. Peserta yang hadir berfoto bersama seperti pada gambar berikut:

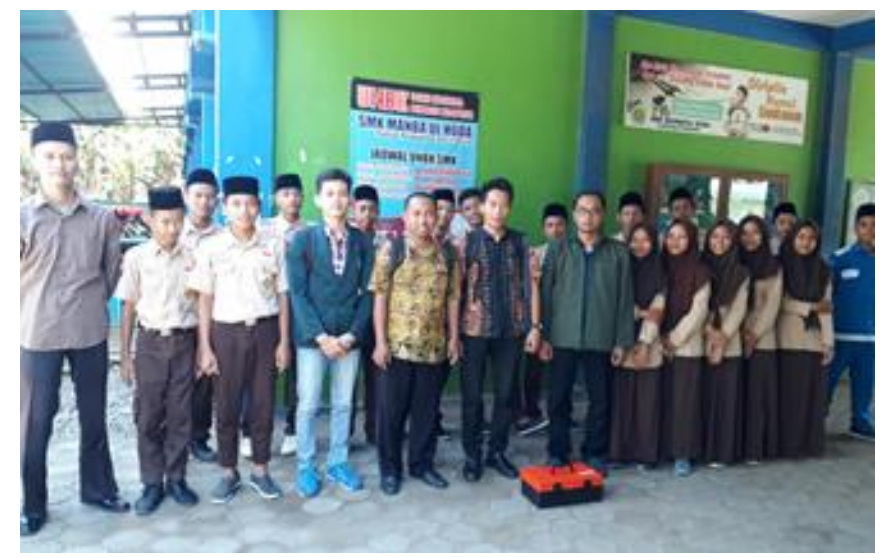

Gambar 1. Pelaksanaan kegiatan pengabdian

Pelatihan yang dilaksanakan merupakan control pengaturan lampu LED berjalan dengan control microcontroller Arduino Uno yang dikoneksikan dengan lampu LED.

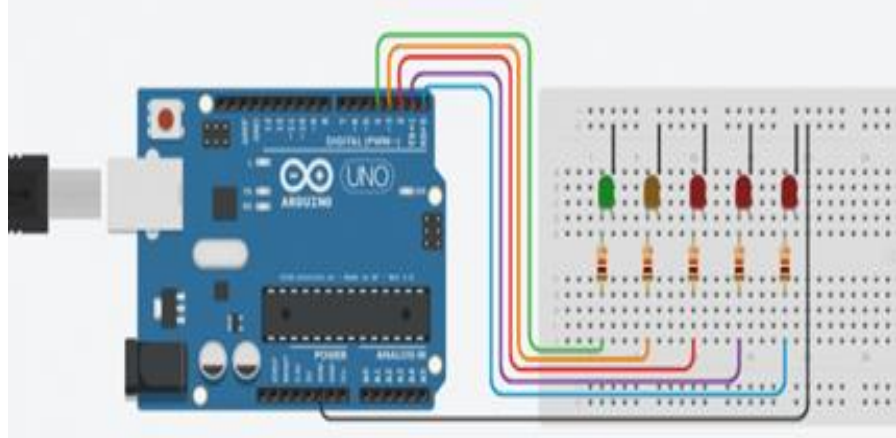

Gambar 2. Rangkaian control Arduino Uno

Pelatihan lanjutan yang dihasilkan dari program pengabdian ini adalah kemampuan siswa dalam bidang elektronika khususnya untuk membuat program dengan software proteus untuk menagpalikasikan microcontroller arduino uno. Luaran lainnya berupa instalasi aplikasi rangkaian microcontroller yang terkoneksi dengan komputer sampai alat berfungsi sesuai dengan program yang dibuat oleh user. 


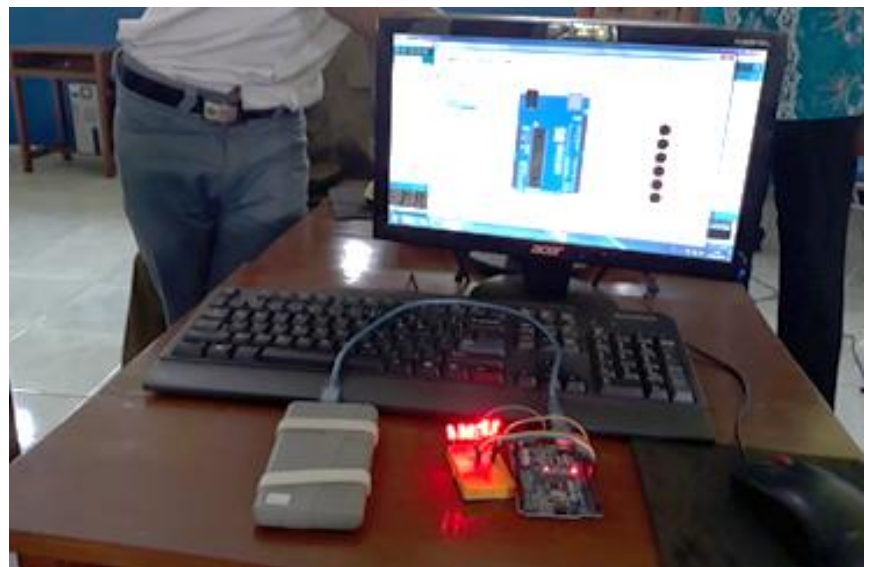

Gambar 3. Hasil aplikasi program microcontroller Arduino Uno

\section{KESIMPULAN}

Berdasarkan hasil kegiatan yang sudah dilaksanakan oleh tim, maka didapatkan hasil kesimpulan.

1. Antusias siswa dalam mengikuti kegiatan pengabdian pelatihan dan pendampingan pembuatan aplikasi software microcontroller Arduino Uno sangat tinggi, dibuktikan dengan jumlah kehadiran mencapai 95\% peserta yang hadir selama kegiatan berlangsung.

2. Siswa memiliki kemampuan untuk mengembangkan aplikasi software microcontroller Arduino Uno yang diterapkan pada simulasi dan control led.

\section{DAFTAR RUJUKAN}

Wiranto Ifan, 2015. Pelatihan Keterampilan Dasar Komputer dan Teknologi Informasi Bagi Siswa Sekolah Dasar dan Perangkat Desa Alata Karya Kecamatan Kwandang Kabupaten GorontaloUtara. Universitas Negeri Gorontalo. Gorontalo.

Hari Wibawanto, 2012. Elektronika Dasar Pengenalan Praktis. E-Media Solusindo. Jakarta.

Pujiriyanto, 2009, Peranan Sebagai Media Pembelajaran Bagi Anak. Dinamika Pendidikan. Vol. 16. No. 1, FIP, Universitas Negeri Gorontalo.

Malvino, B. 2010. Prinsip-Prinsip Elektronika. Edisi IV, Bina Adiaksara. Erlangga. Jakarta.

Jejen Musfah, 2012. Peningkatan Kompetensi Guru Melalui Pelatihan dan Sumber Belajar Teori dan Praktik. Cetakan Ke-2. Kencana. Bandung. 